\title{
Indicadores de gestión del GAD Municipalidad de Quero
}

\section{Introducción}

La gestión de los Gobiernos Autónomos Descentralizados - GAD, se rigen al Código Orgánico de Organización Territorial, Autonomía y Descentralización - COOTAD y al Código Orgánico de Planificación y Finanzas Públicas COPFP, por lo tanto, las decisiones deben reflejar una organización articulada con una participación ciudadana activa.

El presente artículo analiza el comportamiento de los principales indicadores financieros inherentes a la gestión del GAD Municipal de Quero, para esto se cuenta con el resumen de ingresos y gastos de las cédulas presupuestarias de los años 2010 al 2014, proporcionado por la Dirección Financiera de la institución.

\section{Ingresos}

En función de la ejecución presupuestaria, en el periodo de análisis los ingresos no han variado significativamente. En el año 2010 se registra un valor de USD 4'442.712,28 y en el 2014 de USD 6'088.462,33. El crecimiento promedio anual es $8,6 \%$.

De la misma manera, el crecimiento promedio anual de los grupos de ingreso más representativo son los corrientes $(16,8 \%)$; seguido de financiamiento $(15,1 \%)$ y finalmente de capital $(4,4 \%)$.

Tabla 1: Resumen de ingresos del GAD Municipal de Quero, valores devengados en dólares

Periodo 2010-2014

\begin{tabular}{|c|c|c|c|c|c|c|}
\hline Detalle Año & 2010 & 2011 & 2012 & 2013 & & 2014 \\
\hline Ingresos corrientes & $\$ 1005.939,98$ & $\$ 1318.052,43$ & $\$ 1491.428,78$ & $\$ 1^{\prime} 695.899,76$ & $\$$ & $1^{\prime} 850.919,90$ \\
\hline Impuestos & $\$ \quad 102.391,81$ & $\$ 104.362,65$ & $\$ \quad 147.579,11$ & $\$ 134.620,20$ & $\$$ & $170.108,01$ \\
\hline Tasas y contribuciones & $\$ \quad 130.211,95$ & $\$ 322.635,87$ & $\$ \quad 401.524,55$ & $\$ 474.452,89$ & $\$$ & $498.934,17$ \\
\hline Venta de bienes y servicios & $83.385,76$ & $\$ 75.644,62$ & $74.349,65$ & $81.794,24$ & $\$$ & $85.419,93$ \\
\hline Renta de inversiones y multas & $38.085,38$ & $64.958,38$ & $65.058,77$ & $81.317,56$ & $\$$ & $37.069,92$ \\
\hline Transferencias y donaciones corrientes & $\$ \quad 645.295,52$ & $\$ 711.544,05$ & $\$ \quad 800.780,46$ & $\$ \quad 911.811,33$ & $\$$ & $1^{\prime} 039.378,58$ \\
\hline Otros ingresos & $6.569,56$ & $\$ \quad 38.906,86$ & $2.136,24$ & $11.903,54$ & $\$$ & $20.009,29$ \\
\hline Ingresos de capital & $\$ 2301.502,43$ & $\$ 2$ 2'978.303,67 & $\$ 22^{\prime} 688.810,37$ & $\$ 2^{\prime} 777.270,04$ & $\$$ & $2{ }^{\prime} 625.969,30$ \\
\hline Venta de activos no financieros & $\$-$ & $\$-$ & $\$-$ & $\$-$ & & $\$-$ \\
\hline $\begin{array}{l}\text { Transferencias y donaciones de } \\
\text { capital e inversión }\end{array}$ & $\$-$ & $\$-$ & $\$-$ & $\$-$ & & $\$-$ \\
\hline Recuperación de inversiones & $\$ 2,301.502,43$ & $\$ 2978.303,67$ & $\$ 22^{\prime} 688.810,37$ & $\$ 2 ' 777.270,04$ & $\$$ & $2^{\prime} 625.969,30$ \\
\hline Ingresos de financiamiento & $\$ 1^{\prime} 135.269,87$ & $\$ 903.853,51$ & $\$ \quad 703.497,97$ & $\$ 1^{\prime} 112.124,21$ & $\$$ & $1^{\prime} 611.573,13$ \\
\hline Financiamiento público & $\$ \quad 153.264,00$ & $\$ \quad 116.998,91$ & $58.501,09$ & $\$-$ & & $\$-$ \\
\hline Saldos disponibles & $\$ \quad 493.360,00$ & $\$ 163.175,99$ & $321.691,81$ & $\$ 773.993,00$ & $\$$ & 1'327.310,66 \\
\hline Cuentas pendientes por cobrar & $\$ \quad 488.645,87$ & $\$ \quad 623.678,61$ & $323.305,07$ & $\$ 338.131,21$ & $\$$ & $284.262,47$ \\
\hline Total & $\$ 4^{\prime} 442.712,28$ & $\$ 5^{\prime} 200.209,61$ & $\mid \$ 4^{\prime} 883.737,12$ & $\$ 5^{\prime} 585.294,01$ & $\$$ & $6^{\prime} 088.462,33$ \\
\hline
\end{tabular}

En los cinco años analizados, el grupo más representativo son los ingresos de capital, con un promedio del $51 \%$ del total de ingresos; según el clasificador presupuestario de ingresos y gastos del sector público, estos "provienen de la venta de bienes de larga duración, venta de intangibles, de la recuperación de inversiones y de la recepción de fondos como transferencias o donaciones sin contraprestación, destinadas a la inversión en la formación bruta de capital. Su devengamiento produce contablemente modificaciones directas en la composición patrimonial del Estado." (Ministerio de Finanzas., 2014:20). Mientras que los de menos participación, en promedio, son los corrientes con un $28,1 \%$ y los de financiamiento con el $20,9 \%$.

Figura 1: Grupos de ingresos devengados del GAD Municipal de Quero Periodo 2010-2014

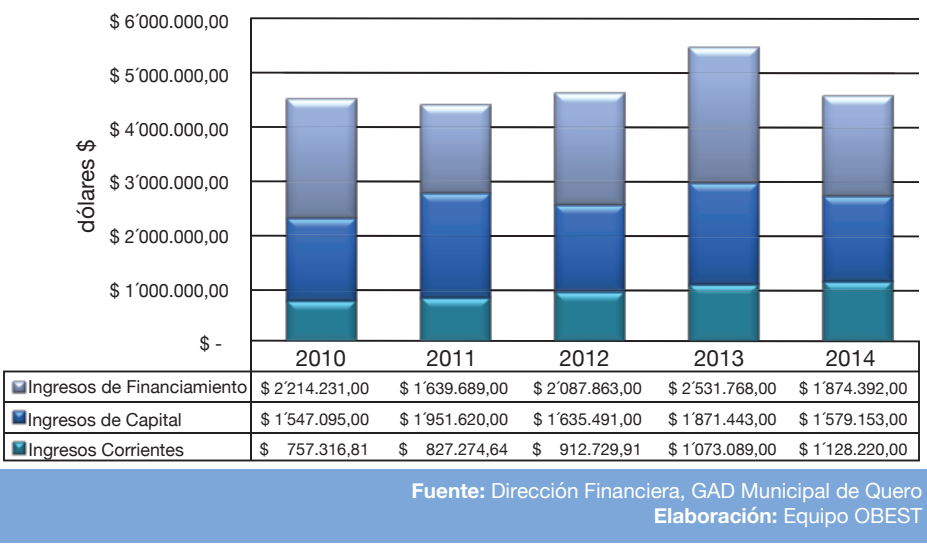

\section{Gastos}

Los gastos del GAD Municipal de Quero para el año 2010 registran USD 3'545.696,27, y para el 2014 descienden a USD 3'255.861,96, se evidencia un crecimiento promedio del $0,2 \%$ en los cinco años de análisis.

En el grupo de gastos que corresponde al periodo 2010-2014, se observa un incremento promedio en los rubros de: capital (45,7\%), corrientes (16,5\%) e inversión (1,45\%). La aplicación del financiamiento refleja un decrecimiento $(-31,3 \%)$.

Tabla 2: Resumen de gastos del GAD Municipal de Quero, valores devengados en dólares Periodo 2010-2014

\begin{tabular}{|c|c|c|c|c|c|c|c|c|}
\hline Detalle Año & & 2010 & & 2011 & & 2012 & 2013 & 2014 \\
\hline Gastos corrientes & $\$$ & $654.434,08$ & & $1^{\prime} 030.809,08$ & & $119.573,33$ & $\$ 1^{\prime} 053.330,20$ & $\$ 1^{\prime} 112.292,96$ \\
\hline Gastos de personal & $\$$ & $428.831,99$ & $\$$ & $736.460,75$ & $\$$ & $834.684,10$ & $\$ \quad 820.002,24$ & $934.130,21$ \\
\hline Bienes y servicios de consumo & $\$$ & $115.025,57$ & $\$$ & $165.755,89$ & $\$$ & $141.666,82$ & $\$ \quad 149.924,51$ & $124.187,25$ \\
\hline Gastos financieros & $\$$ & $59.886,38$ & $\$$ & $55.221,50$ & $\$$ & $34.946,04$ & $15.739,60$ & $7.000,00$ \\
\hline Otros gastos corrientes & $\$$ & $21.841,47$ & $\$$ & $1.808,92$ & $\$$ & $4.017,40$ & $3.411,12$ & $1.495,58$ \\
\hline Transferencias y donaciones corrientes & $\$$ & $28.848,67$ & $\$$ & $71.562,02$ & $\$$ & $104.258,97$ & $64.252,73$ & $45.479,92$ \\
\hline Gastos de inversión & & $.958 .022,61$ & & $2.486 .638,73$ & & $079.409,62$ & $\$ 2.697 .206,44$ & $\$ 1.773 .011,11$ \\
\hline Gastos en personal para inversión & $\$$ & $408.002,90$ & $\$$ & $502.066,51$ & $\$$ & $563.865,56$ & $\$ \quad 553.414,70$ & \begin{tabular}{|l|}
$540.126,98$ \\
\end{tabular} \\
\hline Bienes y servici & $\$$ & $502.194,42$ & $\$$ & $688.704,95$ & $\$$ & $627.742,74$ & $\$ \quad 603.113,56$ & $\$ 311.905,58$ \\
\hline Obras públicas & $\$$ & $808.352,53$ & & $1.276 .473,38$ & $\$$ & $709.367,54$ & $\$ 1.317 .980,50$ & $\$ \quad 780.453,99$ \\
\hline Otros gastos de inversión & & $\$-$ & & $\$-$ & $\$$ & $16.487,51$ & $17.961,70$ & $26.999,92$ \\
\hline $\begin{array}{l}\text { Transferencias } y \text { donaciones } \\
\text { para inversión }\end{array}$ & $\$$ & $239.472,76$ & $\$$ & $19.393,89$ & $\$$ & $161.946,27$ & $\$ \quad 204.735,98$ & $113.524,64$ \\
\hline Gastos de capital & $\$$ & $485.684,36$ & $\$$ & $661.780,31$ & $\$$ & $69.004,14$ & $\$ \quad 196.285,00$ & \$ $297.599,42$ \\
\hline Bienes de larga duración & $\$$ & $482.684,36$ & $\$$ & $608.369,22$ & $\$$ & $53.088,58$ & $\$ \quad 196.285,00$ & $\$ \quad 297.599,42$ \\
\hline Inversiones financieras & & $\$-$ & $\$$ & $36.374,09$ & $\$$ & $14.465,56$ & $\$-$ & $\$-$ \\
\hline $\begin{array}{l}\text { Transferencias y donaciones } \\
\text { para inversión }\end{array}$ & $\$$ & $3.000,00$ & $\$$ & $17.037,00$ & $\$$ & $1.450,00$ & $\$-$ & $\$-$ \\
\hline Aplicación del financiamiento & $\$$ & $447.555,22$ & $\$$ & $356.072,59$ & $\$$ & $372.435,14$ & $\$ \quad 206.178,15$ & $72.958,47$ \\
\hline Amortización de la deuda & $\$$ & $397.530,44$ & & $\$-$ & $\$$ & $372.435,14$ & $\$ \quad 206.178,15$ & $72.958,47$ \\
\hline Pasivo circulante & $\$$ & $50.024,78$ & $\$$ & $356.072,59$ & & $\$-$ & $\$-$ & $\$-$ \\
\hline Gasto total & & $545.696,27$ & & "535.300,71 & & $640.422,23$ & $\$ 4^{\prime} 152.999,79$ & \$ 3'255.861,96 \\
\hline
\end{tabular}

Fuente: Dirección Financiera, GAD Municipal de Quero 
En el periodo 2010-2014, el grupo más representativo son los gastos de inversión, con un promedio del $57,5 \%$ del total de gastos que "son los recursos destinados al incremento patrimonial del Estado, mediante actividades operacionales de inversión, comprendido en programas sociales o proyectos institucionales de ejecución de obra pública, conformados por gastos en personal, bienes y servicios destinados a la inversión, obras públicas y transferencias de inversión" (Ministerio de Finanzas., 2014:73). Los gastos corrientes con un $26 \%$, de capital en $8,9 \%$ y la aplicación del financiamiento con $7,6 \%$.

Figura 2: Grupos de gastos del GAD Municipal de Quero, valores devengados Periodo 2010-2014

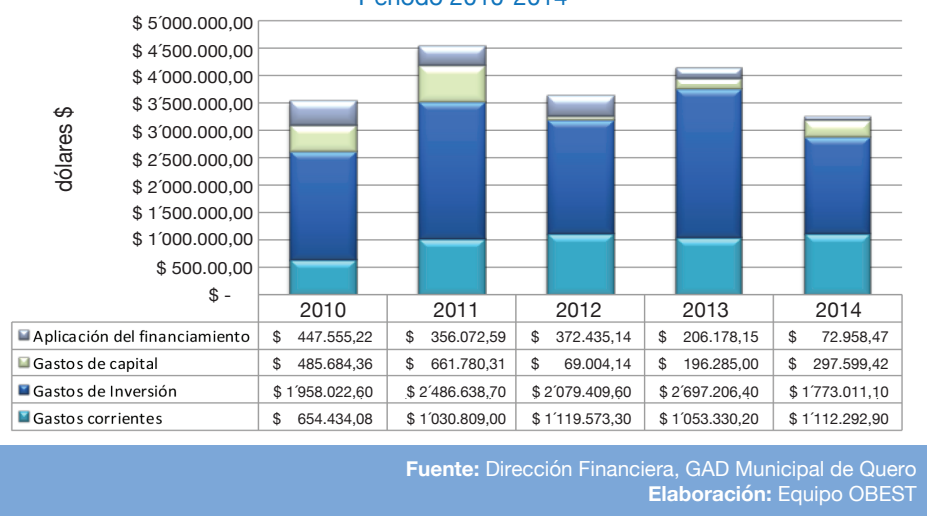

\section{Indicadores de gestión}

Como parte de las acciones tomadas por el GAD Municipal de Quero, en el periodo 2010-2014, se analizan nueve indicadores que permiten evaluar su desempeño y resultados.

\section{Autonomía}

Se considera como autonomía a la participación de los ingresos propios sobre los ingresos totales; es decir, entre mayor sea este indicador es mejor porque demuestra la autonomía financiera que posee el gobierno seccional, la situación óptima es que supere el $80 \%$, en el periodo de análisis el promedio es 23,30\%. El 2013, con mayor capacidad de generación de recursos o autofinanciamiento llega al 35\%; mientras que, el año más bajo en relación al promedio fue 2014 con el $18 \%$.

Figura 3: Indicador de autonomía financiera del GAD Municipal de Quero Periodo 2010-2014

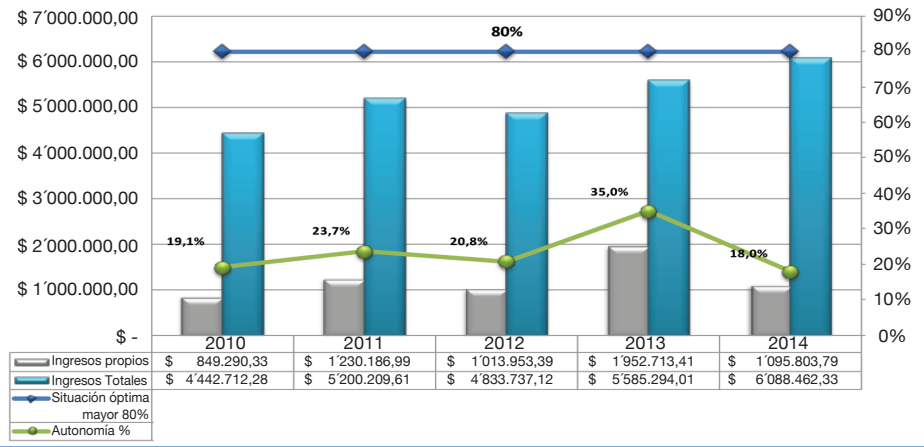

Fuente: Dirección Financiera, GAD Municipal de Quero
Elaboración: Equipo OBEST

\section{Dependencia}

Es la relación que existe entre los ingresos por transferencias que realiza el gobierno central sobre los ingresos totales, mientras este valor sea menor, la gestión institucional se califica como positiva, la situación óptima es que llegue a ser menor que el $20 \%$. En el caso del GAD de Quero presenta un promedio de 67\%. En el periodo 2010-2014, el mejor año es 2011 que registra el $70,96 \%$ y el valor más alto en el año 2010 con 66,33\%.

Figura 4: Indicador de dependencia financiera del GAD Municipal de Quero Periodo 2010-2014

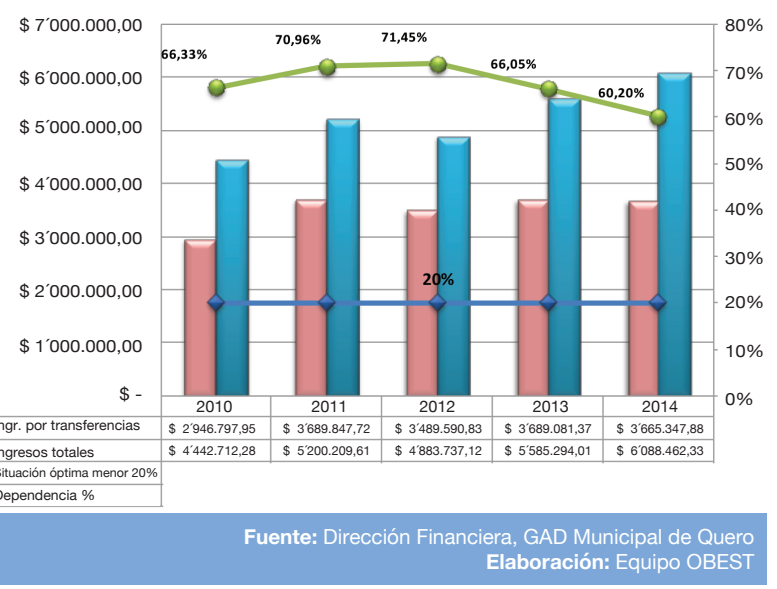

\section{Ahorro corriente}

Para evaluar la capacidad de endeudamiento del GAD Municipal de Quero, se realiza la diferencia del ingreso corriente frente al gasto corriente, la situación óptima es que el resultado sea positivo, el promedio es USD 478.360,24 y los mejores años son 2013 y 2014.

Figura 5: Ahorro corriente del GAD Municipal de Quero, en dólares Periodo 2010-2014

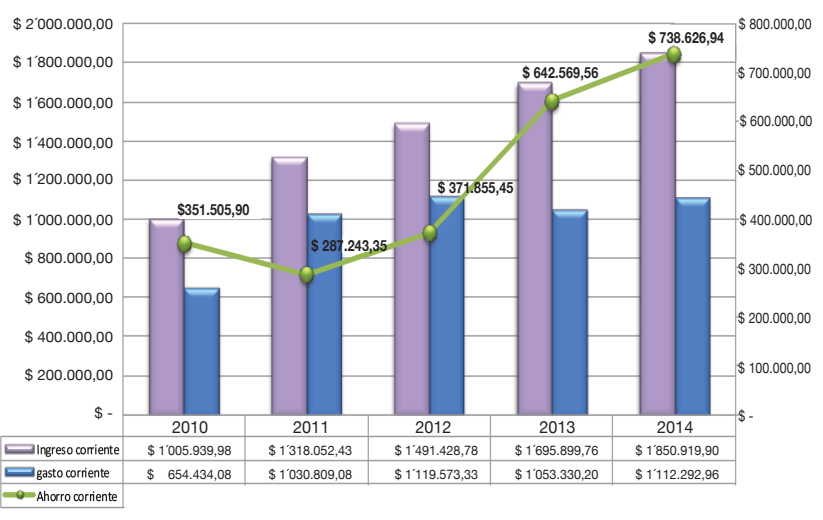

Fuente: Dirección Financiera, GAD Municipal de Quero Elaboración: Equipo OBEST

\section{Solvencia}

Es la capacidad de cumplir con obligaciones a corto plazo; también, de qué manera el GAD Municipal de Quero financia sus actividades operativas. La meta de este indicador es que sea igual o mayor al $100 \%$, el promedio es $148,44 \%$ de los años 2010 al 2014, lo que indica, que la utilización de los recursos cubre los gastos de capital o propician ahorro corriente. 
Figura 6: Solvencia financiera del GAD Municipal de Quero Periodo 2010-2014

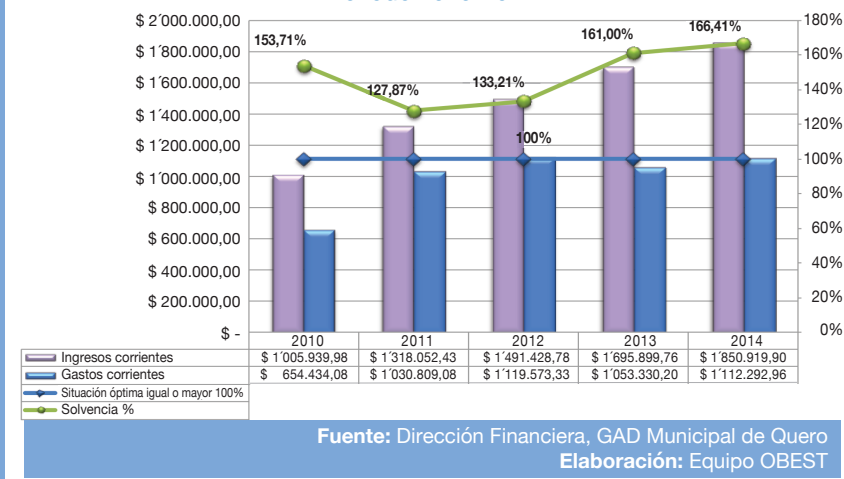

\section{Autosuficiencia}

Evalúa la capacidad de Financiamiento del GAD de Quero para hacer frente a los gastos operativos y de administración, la situación óptima es que sea mayor al 100\%. En los años de estudio se evidencia un promedio del $124,72 \%$, sin embargo el año 2013 es el más representativo.

Figura 7: Autosuficiencia financiera del GAD Municipal de Quero Periodo 2010-2014

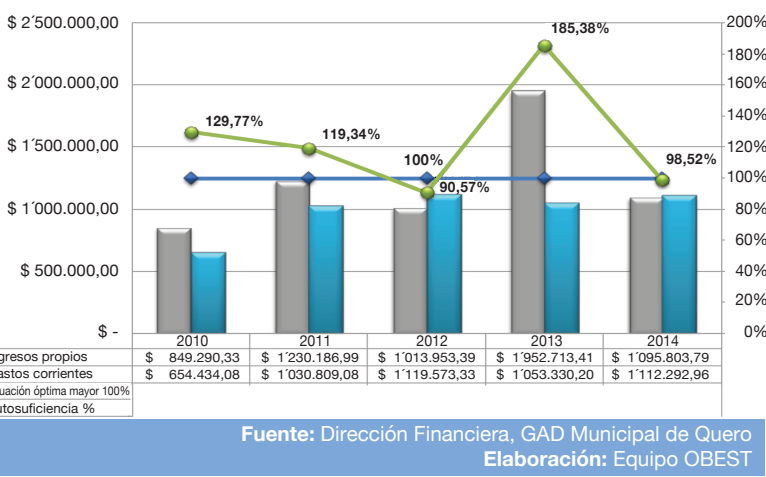

\section{Autosuficiencia Mínima}

Si los resultados superan a la meta óptima que sea mayor al $100 \%$, significa que el GAD de Quero puede cubrir los gastos de remuneraciones con sus recursos propios. El $238,14 \%$ corresponde al promedio del periodo de análisis, pero el año 2013 supera la meta con el 196,90\%.

Figura 8: Autosuficiencia mínima del GAD Municipal de Quero Periodo 2010-2014
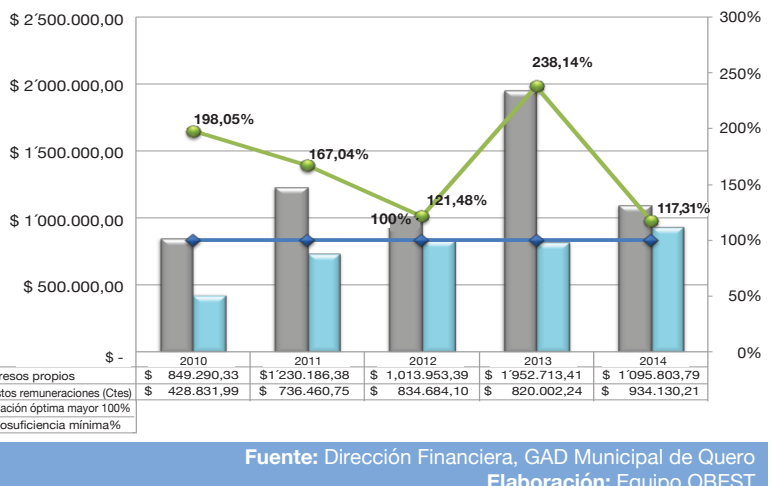

\section{Peso de la remuneración}

El efecto de las remuneraciones del GAD Municipal de Quero con relación al gasto corriente, se considera una situación óptima si es menor al $60 \%$. Se evidencia un promedio del 74,67\% en el periodo de análisis; el año 2010 se acerca a la meta.
Figura 9: Efecto de las remuneraciones del GAD Municipal de Quero Periodo 2010-2014

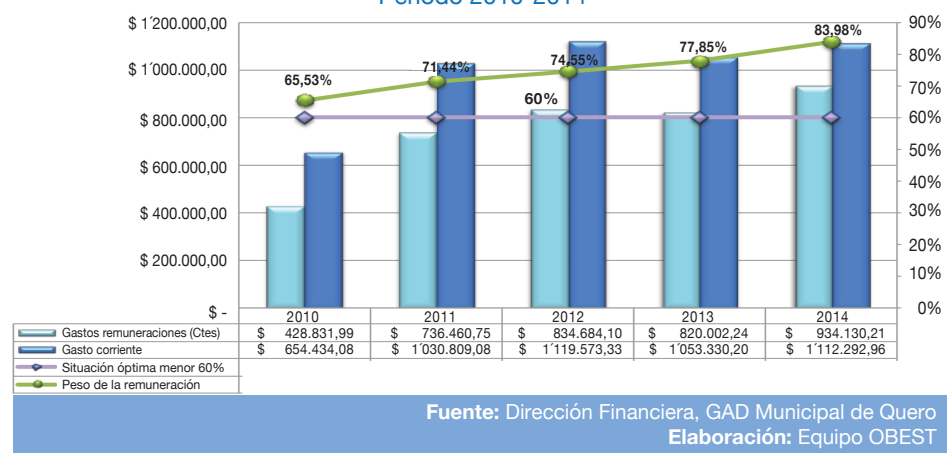

\section{Remuneración y presupuesto}

EI GAD Municipal de Quero, excede en el porcentaje establecido para remuneraciones frente al presupuesto total, la situación óptima para este indicador, es que tenga un máximo del 30\%. El promedio de $33,54 \%$ pertenece al periodo de análisis, los porcentajes más altos se registran en los años 2012, 2013 y 2014; mientras que los años que cumplen con la meta son 2010 y 2011.

Figura 10: Remuneración y presupuesto del GAD Municipal de Quero Periodo 2010-2014

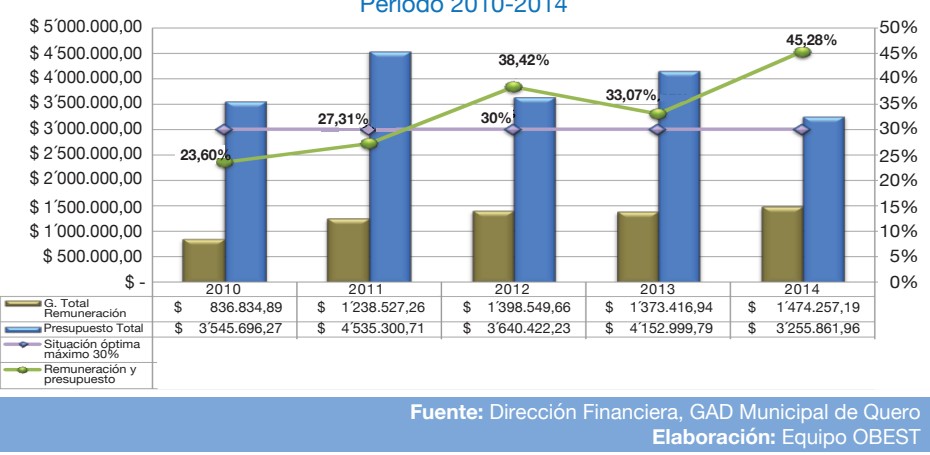

\section{Ingreso y egreso per-cápita}

El ingreso promedio propio por habitante que percibe el GAD Municipal de Quero en el periodo 2010-2014 consta de USD 40,44; mientras que, el egreso en inversión refleja USD 109,06 per-cápita.

Figura 11: Ingreso y egreso per cápita del GAD Municipal de Quero Periodo 2010-2014

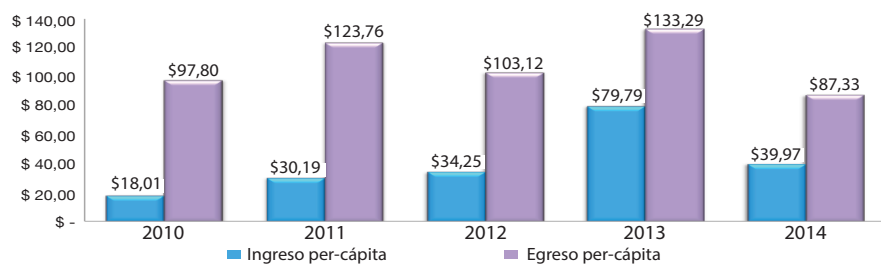
Fuente: Dirección Financiera, GAD Municipal de Quero

Referencias:

- Asamblea Nacional, Código Orgánico de Planificación y Finanzas Públicas, 2010

- Gobierno Autónomo Descentralizado Municipal de Quero, Resumen de ingresos y gastos presupuestarios, Dirección Financiera, periodo 2010 - 2014

- Instituto Nacional de Estadística y Censos, Ecuador en cifras, proyección de la población ecuatoriana, por años calendario, según cantones, 2010-2020

- Ministerio de Finanzas, Clasificador presupuestario de ingresos y gastos del sector público. Actualizado al 12 de junio de 2014.

Elaboración:

Econ. Juan Pablo Martínez Mesías, Mg Lic. Lorena Rivera Badillo, Msc. 